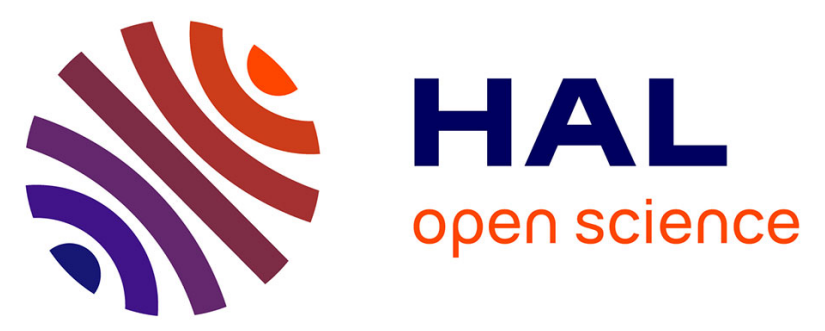

\title{
Novel Naphthalimide-amine Based Photoinitiators Operating under Violet and Blue LEDs and Usable for Various Polymerization Reactions and Synthesis of Hydrogels
}

Nicolas Zivic, Jing Zhang, David Bardelang, Frédéric Dumur, Pu Xiao, Thomas Jet, Davy-Louis Versace, Céline Dietlin, Fabrice Morlet-Savary, Bernadette Graff, et al.

\section{- To cite this version:}

Nicolas Zivic, Jing Zhang, David Bardelang, Frédéric Dumur, Pu Xiao, et al.. Novel Naphthalimideamine Based Photoinitiators Operating under Violet and Blue LEDs and Usable for Various Polymerization Reactions and Synthesis of Hydrogels. Polymer Chemistry, 2016, 7, pp.418-429. 10.1039/C5PY01617G . hal-01394907

\section{HAL Id: hal-01394907 \\ https://hal-amu.archives-ouvertes.fr/hal-01394907}

Submitted on 10 Nov 2016

HAL is a multi-disciplinary open access archive for the deposit and dissemination of scientific research documents, whether they are published or not. The documents may come from teaching and research institutions in France or abroad, or from public or private research centers.
L'archive ouverte pluridisciplinaire HAL, est destinée au dépôt et à la diffusion de documents scientifiques de niveau recherche, publiés ou non, émanant des établissements d'enseignement et de recherche français ou étrangers, des laboratoires publics ou privés. 


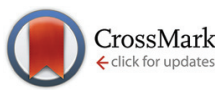

Cite this: Polym. Chem., 2016, 7, 418

\title{
Novel naphthalimide-amine based photoinitiators operating under violet and blue LEDs and usable for various polymerization reactions and synthesis of hydrogels $\dagger$
}

\author{
Nicolas Zivic, ${ }^{b}$ Jing Zhang, ${ }^{a}$ David Bardelang, ${ }^{\mathrm{b}}$ Frédéric Dumur, ${ }^{\mathrm{b}}$ Pu Xiao, ${ }^{\text {a }}$ \\ Thomas Jet, ${ }^{a, c}$ Davy-Louis Versace ${ }^{c}$ Céline Dietlin, ${ }^{a}$ Fabrice Morlet-Savary, ${ }^{a}$ \\ Bernadette Graff, ${ }^{a}$ Jean Pierre Fouassier, $\star^{a}$ Didier Gigmes ${ }^{b}$ and Jacques Lalevée*a
}

\begin{abstract}
A series of naphthalimide derivatives containing tertiary amine groups (DNNDs) have been prepared. Some of these derivatives (e.g. DNND3, DNND4 and DNND5) exhibit interesting shifted absorption so that they can be utilized as versatile photoinitiators upon exposure to various violet and blue LEDs $(385,405$, 455 and $470 \mathrm{~nm}$ ). They are particularly efficient for the cationic photopolymerization of an epoxide and the free radical photopolymerization of an acrylate. The thiol-ene photopolymerization, as well as the synthesis of interpenetrating polymer networks (of epoxide/acrylate blend) IPNs, is feasible. Remarkably, the production of hydrogels can also be easily achieved using a DNND derivative after inclusion in a cyclodextrin cavity. The photochemical mechanisms have been comprehensively investigated by steady state photolysis, Electron Spin Resonance (ESR), fluorescence, electrochemistry and laser flash photolysis and discussed in detail.
\end{abstract}

Received 7th October 2015 Accepted 30th October 2015 DOI: $10.1039 / \mathrm{c} 5 \mathrm{py} 01617 \mathrm{~g}$ www.rsc.org/polymers
PIs and PISs for the free radical polymerization (FRP) of acrylates, the cationic polymerization (CP) of epoxides, the concomitant FRP/CP of acrylates/epoxides, the thiol-ene polymerization, the polymerization of water-borne systems, the two-photon polymerization or the controlled polymerization.

Mercury-based UV lamps have been largely used in industrial applications. However, it is necessary and urgent to find suitable alternatives to $\mathrm{Hg}$ lamps due to environmental concerns. In addition, the Governing Council of the United Nations Environment Program has also been encouraging the reduction of mercury-containing devices (Minamata Convention on Mercury). Recently, the light-emitting diode (LED) technology for photopolymerization reactions (violet LED e.g. $385 \mathrm{~nm}, 395 \mathrm{~nm}$ and $405 \mathrm{~nm}$, blue LED e.g. 455 and $470 \mathrm{~nm}$ ) has emerged and gained widespread acceptance owing to a lot of advantages including faster on/off switching, lower heat generation (absence of IR light), lower energy consumption, longer lamp lifetime, absence of ozone release, and improved robustness, to name just a few. ${ }^{26,27}$ The design of specifically adapted high-performance PISs is one of the most significant factors for successful further development of LED based devices in the photopolymerization area. Recent examples of such studies can be found e.g. in ref. 18, 28, 29. A particularly huge challenge is the development of highly versatile PISs that are able to efficiently initiate upon ecofriendly LEDs all the photopolymerization modes: (i) the free radical polymerization, 
(ii) the cationic polymerization, (iii) the thiol/ene, (iv) the synthesis of an interpenetrating polymer network (IPN) and (v) the polymerization in water for hydrogel synthesis. In our previous studies, various naphthalimide or isoquinolinone derivatives $^{30-35}$ have been developed as photoinitiators, and the derivatives with suitable substituents exhibited excellent photoinitiating ability of polymerization. It is still interesting to further investigate the substituent effect of these kinds of derivatives on their photochemical properties and expand the knowledge in the field of photoinitiators.

In the present paper, we focus our attention on the introduction of different substituents onto the $N$-[2-(dimethylamino)ethyl]-1,8-naphthalimide skeleton. Four compounds containing nitro (DNND1 and DNND2) or amino (DNND3) substituents or anthracene (DNND4) have been prepared [two of them are anti-cancer drugs referred to as amonafide (DNND3) and azonafide (DNND4) $)^{36}$. The fifth compound is a little different as it belongs to the isoquinolinone series (DNND5). These five chemicals have been incorporated as PIs into photoinitiating systems where they are combined with an iodonium salt (Iod) or a chlorotriazine (R-Cl) and optionally $N$-vinylcarbazole (NVK) or an amine (MDEA or EDB). The FRP of a triacrylate, the $\mathrm{CP}$ of a diepoxide, the thiol-ene polymerization of a trithiol/divinylether blend, the synthesis of an interpenetrating polymer network from an epoxy/acrylate blend, and the formation of hydrogels (using the PI encapsulated into a cyclodextrin cavity) upon exposure to various violet and blue LEDs (emission wavelengths from $385 \mathrm{~nm}$ to $470 \mathrm{~nm}$ ) have been investigated by Real-Time Fourier Transform Infrared spectroscopy (RT-FTIR). Moreover, a water-soluble DNND/ cyclodextrin complex has been used for the production of hydrogels. The absorption properties are studied by molecular orbital calculations and the photochemical mechanisms involved in the formation of the reactive species have been investigated by steady state photolysis, fluorescence, cyclic voltammetry, electron spin resonance spin trapping and laser flash photolysis techniques.

\section{Experimental}

\section{Materials}

The investigated photoinitiators $-N$-[2-(dimethylamino)ethyl]1,8-naphthalimide derivatives (DNND1 and DNND2), amonafide (DNND3), azonafide (DNND4), and isoquinolinone derivative (DNND5) - are shown in Scheme 1, while other chemical compounds are depicted in Scheme 2. DNND1-DNND5 were synthesized according to the procedures presented in detail in the ESI. $\uparrow$ In DNND5, isomers also existed in the product as presented in the ESI. $\dagger$ Diphenyliodonium hexafluorophosphate (Iod), $N$-vinylcarbazole (NVK), methyl diethanolamine (MDEA), 2,4,6-tris(trichloromethyl)-1,3,5-triazine (R-Cl), camphorquinone (CQ), tri(ethylene glycol)divinyl ether (DVE-3), trimethylolpropane tris(3-mercaptopropionate) (trithiol), and the other reagents and solvents were purchased from Sigma-Aldrich or Alfa Aesar and used as received without

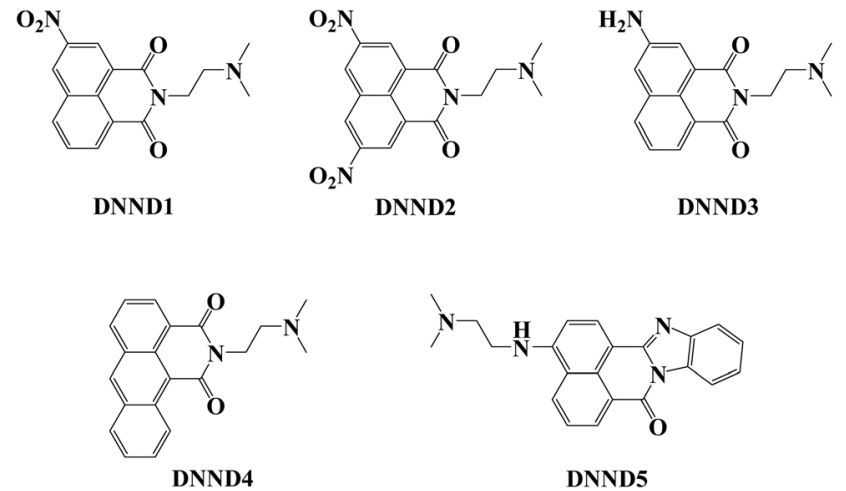

Scheme 1 Chemical structures of the DNNDs investigated as photoinitiators in this study.

further purification. Bisacylphosphine oxide (Irgacure 819 or BAPO) was obtained from BASF. Trimethylolpropane triacrylate (TMPTA) and (3,4-epoxycyclohexane)methyl 3,4-epoxycyclohexylcarboxylate (EPOX) were obtained from Allnex and used as benchmark monomers for radical and cationic photopolymerizations. Hydroxyethylacrylate (HEA) and hydroxyethylmethacrylate (HEMA) from Sigma-Aldrich were used as reference monomers for polymerization in water. Sulfobutylether- $\beta$-cyclodextrin (SBE- $\beta$-CD) was a generous gift of Clemens Glaubitz (Institute for Biophysical Chemistry, Goethe University Frankfurt, Germany).

\section{Irradiation sources}

Different light sources were used for the irradiation of photocurable samples: LEDs centered at $365 \mathrm{~nm}$ (M365L2 - ThorLabs; $18 \mathrm{~mW} \mathrm{~cm}^{-2}$ ), $385 \mathrm{~nm}$ (M385L2 - ThorLabs; $\sim 27 \mathrm{~mW}$ $\mathrm{cm}^{-2}$ ), $405 \mathrm{~nm}$ (M405L2 - ThorLabs; $\sim 110 \mathrm{~mW} \mathrm{~cm}^{-2}$ ), $455 \mathrm{~nm}$ (M455L3 - ThorLabs; $\sim 80 \mathrm{~mW} \mathrm{~cm}^{-2}$ ), and $470 \mathrm{~nm}$ (M470L3 ThorLabs; $\sim 70 \mathrm{~mW} \mathrm{~cm}^{-2}$ ), and a halogen lamp (Fiber-Lite, DC-950; polychromatic light; incident light intensity: $\sim 12 \mathrm{~mW}$ $\mathrm{cm}^{-2}$ in the $370-800 \mathrm{~nm}$ range). The emission spectra of the irradiation sources are given in the ESI (Fig. S1-S6†).

\section{Computational procedure}

Molecular orbital calculations were carried out using the Gaussian 03 package. The electronic absorption spectra for the DNND derivatives were calculated from the time-dependent density functional theory at the B3LYP/6-31G* level on the relaxed geometries calculated at the UB3LYP/6-31G* level; the molecular orbitals involved in these transitions were extracted..$^{37,38}$ The geometries were frequency checked.

\section{Photopolymerization experiments}

For photopolymerization experiments, the conditions are given in the figure captions. The photosensitive formulations (25 $\mu \mathrm{m}$ thick) were deposited on a $\mathrm{BaF}_{2}$ pellet in laminate (the formulation is sandwiched between two polypropylene films to avoid the re-oxygenation during the photopolymerization) or under air for irradiation with the different light sources. The 
Additives<smiles>c1ccc(I(c2ccccc2)c2ccccc2)cc1</smiles>

Iod<smiles>CCn1c2ccccc2c2ccccc21</smiles>

NVK<smiles>CC(CCO)CCO</smiles>

MDEA<smiles>CCOC(=O)c1ccc(N(C)C)cc1</smiles>

EDB<smiles>ClC(Cl)(Cl)c1nc(C(Cl)(Cl)Cl)nc(C(Cl)(Cl)Cl)n1</smiles><smiles>O=C(OCC1CCC2CC1C2)C1CCC2OC2C1</smiles>

EPOX<smiles>C=CC(=O)OCC(CC)(COC(=O)C=C)COC(=O)CC</smiles>

TMPTA<smiles>C=COCCOCC</smiles>

DVE-3<smiles>CCC(COC(=O)CCS)(COC(=O)CCS)COC(=O)CCS</smiles>

Scheme 2 Chemical structures of the additives and the monomers.

evolution of the double bond content of TMPTA, the epoxy group content of EPOX, the double bond content of DVE-3, and the thiol $(\mathrm{S}-\mathrm{H})$ content of trithiol were continuously followed by real time FTIR spectroscopy (JASCO FTIR 4100) (9,40 $^{39}$ at about $1630 \mathrm{~cm}^{-1}, 790 \mathrm{~cm}^{-1}, 1620 \mathrm{~cm}^{-1}$, and $2570 \mathrm{~cm}^{-1}$, respectively.

TMPTA, EPOX, DVE-3, and trithiol are multifunctional monomers and the conversion that is mentioned does not correspond to the monomer conversion but to the conversion of the polymerizable functions. For example, converting 50\% of these functions corresponds thus already to a higher monomer conversion (order of magnitude: $75 \%$ for a difunctional monomer and $87.5 \%$ for a trifunctional one).

\section{Photopolymerization in water}

For polymerization in water, DNND4/SBE- $\beta$-CD was combined with methyldiethanolamine (co-initiator) as a Type II photoinitiating system (DNND4/SBE- $\beta$-CD/MDEA). The monomers used, hydroxyethylacrylate (HEA) or hydroxyethylmethacrylate (HEMA), are characterized by a good solubility in water. The monomer dissolved in water and in the presence of a photoinitiating system was irradiated in a glass vial using a LED@405 nm. The polymerization was carried out under air. The water content in the prepared gel was determined by thermogravimetric analysis (TGA) (METTLER - TOLEDO TGA 851e).

\section{Steady state photolysis experiments}

The studied photoinitiators in the presence of an additive (e.g. Iod or R-Cl) in acetonitrile were irradiated with a LED at $405 \mathrm{~nm}$, and the UV-vis spectra were recorded using a JASCO V-530 UV/Vis spectrophotometer at different irradiation times.

\section{Fluorescence experiments}

The fluorescence properties of the investigated photoinitiators in acetonitrile were studied using a JASCO FP-750 spectrofluorimeter. The interaction rate constants $k_{\mathrm{q}}$ between the studied photoinitiator and the quencher were extracted from classical Stern-Volmer $\operatorname{plots}^{4}\left(I_{0} / I=1+k_{\mathrm{q}} \tau_{0}\right.$ [quencher], where
$I_{0}$ and $I$ stand for the fluorescence intensity of the photoinitiator in the absence and presence of the quencher, respectively; $\tau_{0}$ stands for the lifetime of the excited photoinitiator in the absence of a quencher).

\section{Redox potentials}

The oxidation potentials ( $E_{\mathrm{Ox}} v s$. SCE) of the studied photoinitiators were measured in acetonitrile by cyclic voltammetry with tetrabutylammonium hexafluorophosphate $(0.1 \mathrm{M})$ as a supporting electrolyte (Voltalab 6 Radiometer). The procedure has been presented in detail in ref. 41 . The free energy change $\Delta G$ for an electron transfer between photoinitiators and Iod (or R-Cl) can be calculated from the classical Rehm-Weller equation: $\Delta G=E_{\mathrm{ox}}-E_{\mathrm{red}}-E_{\mathrm{S}}\left(\right.$ or $\left.E_{\mathrm{T}}\right)+C$; where $E_{\mathrm{ox}}, E_{\mathrm{red}}, E_{\mathrm{S}}$ (or $E_{\mathrm{T}}$ ), and $C$ are the oxidation potentials of the studied photoinitiators, the reduction potential of Iod (or R-Cl), the excited singlet (or triplet) state energy of the studied photoinitiators, and the electrostatic interaction energy for the initially formed ion pair. ${ }^{42}$ The latter parameter is generally considered negligible in polar solvents.

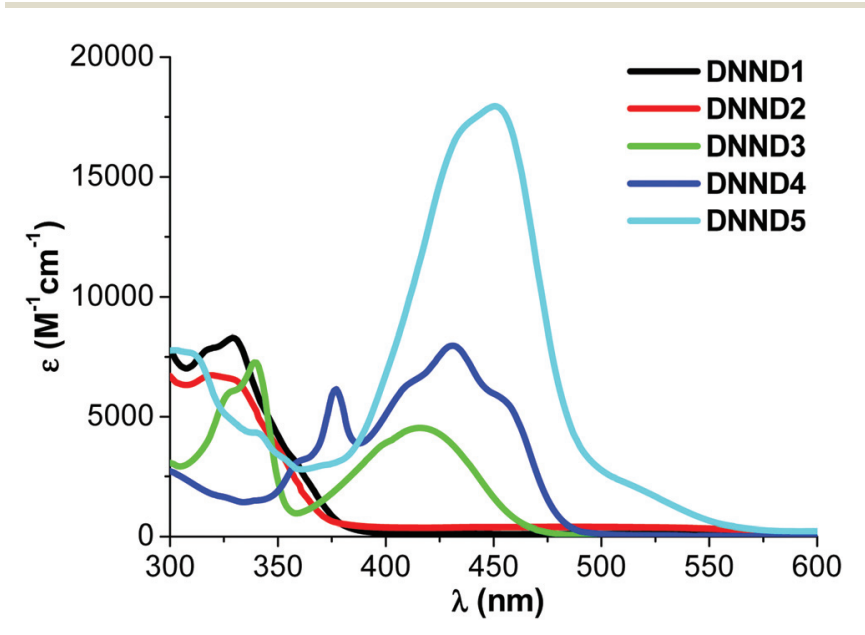

Fig. 1 UV-visible absorption spectra of the DNNDs in acetonitrile. 


\section{ESR spin trapping (ESR-ST) experiment}

ESR-ST experiment was carried out using an X-Band spectrometer (MS 400 Magnettech). The radicals were generated at room temperature upon the LED@405 nm exposure under $\mathrm{N}_{2}$ and trapped by phenyl- $N$-tert-butylnitrone (PBN) according to a procedure ${ }^{43}$ described elsewhere in detail. The ESR spectra simulations were carried out using the WINSIM software.

\section{Laser flash photolysis}

Nanosecond laser flash photolysis (LFP) experiments were carried out using a Q-switched nanosecond Nd/YAG laser $\left(\lambda_{\text {exc }}=355 \mathrm{~nm}, 9 \mathrm{~ns}\right.$ pulses; energy reduced down to $\left.10 \mathrm{~mJ}\right)$ from Continuum (Minilite) and an analyzing system consisting of a ceramic xenon lamp, a monochromator, a fast photomultiplier and a transient digitizer (Luzchem LFP 212). ${ }^{44}$

\section{Results and discussion}

\section{Light absorption properties of the DNNDs}

The UV-visible absorption spectra of the DNNDs in acetonitrile are shown in Fig. 1. As illustrated, DNND1 and DNND2 exhibit a poor ground state absorption in the visible wavelength range $(\lambda>400 \mathrm{~nm})$ with absorption maxima located in the UV range (i.e. $\lambda_{\max }=329 \mathrm{~nm}$ and $\lambda_{\max }=319 \mathrm{~nm}$ for DNND1 and DNND2, respectively). DNND3 presents a red-shifted absorption $\left(\lambda_{\max }=\right.$ $416 \mathrm{~nm}$ ) compared to DNND1, probably due to the amino substituent as already observed in other structures (see e.g. ref. 32, 33). Compared to the previously reported $N$-[2-(dimethylamino)ethyl]-1,8-naphthalimide derivatives (DMAEN1 and DMAEN2) whose maxima were located in the near UV range (i.e. $\lambda_{\max }=387 \mathrm{~nm}$, and $\lambda_{\max }=391 \mathrm{~nm}$, for DMAEN1 and DMAEN2, respectively), ${ }^{29}$ the absorption maxima of DNND3, DNND4 and DNND5 are successfully shifted to longer wave-

(n)

Fig. 2 Highest Occupied Molecular Orbital (HOMO) and Lowest Unoccupied Molecular Orbital (LUMO) of DNNDs at the UB3LYP/6-31G* level (isovalue $=0.04$ ). 


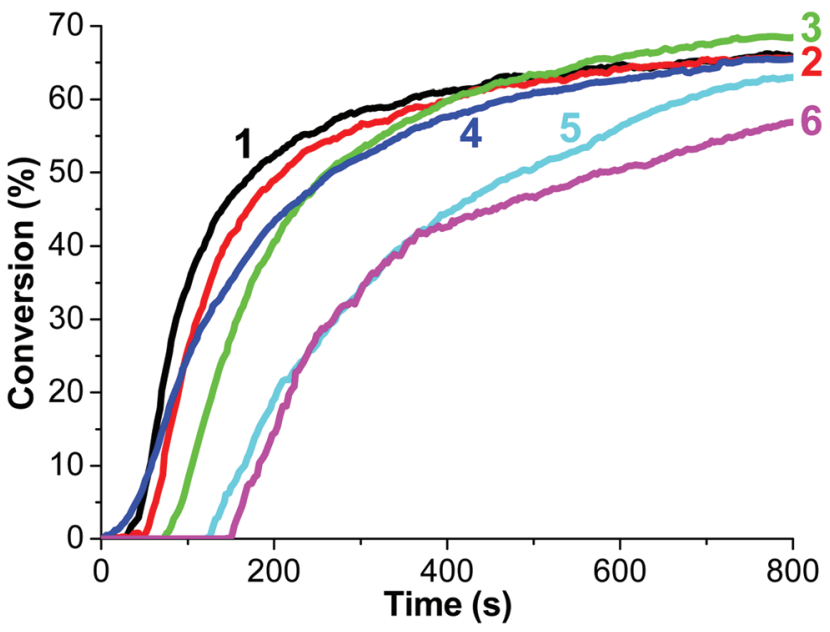

Fig. 3 Photopolymerization profiles of EPOX (epoxy function conversion vs. time) under air in the presence of DNND based PISs: DNND3/lod upon LEDs at $405 \mathrm{~nm}$ (curve 1), $455 \mathrm{~nm}$ (curve 2) or $470 \mathrm{~nm}$ (curve 3) exposure; DNND5/lod upon the LED at $405 \mathrm{~nm}$ exposure (curve 4); DNND4/lod/NVK upon LEDs at $405 \mathrm{~nm}$ (curve 5) or $455 \mathrm{~nm}$ (curve 6) exposure; DNNDs: $0.5 \mathrm{wt} \%$; lod: $2 \mathrm{wt} \%$; NVK: $3 \mathrm{wt} \%$ in the formulations.

length through the present careful chemical structure design (i.e. $\lambda_{\max }=416 \mathrm{~nm}, \varepsilon_{416 \mathrm{~nm}} \sim 4530 \mathrm{M}^{-1} \mathrm{~cm}^{-1} ; \lambda_{\max }=431 \mathrm{~nm}$, $\varepsilon_{431 \mathrm{~nm}} \sim 7970 \mathrm{M}^{-1} \mathrm{~cm}^{-1}$ and $\lambda_{\max }=451 \mathrm{~nm}, \varepsilon_{451 \mathrm{~nm}} \sim 17940$ $\mathrm{M}^{-1} \mathrm{~cm}^{-1}$ for DNND3; DNND4 and DNND5, respectively). The extended light absorption range of these three compounds makes them adapted to a wider range of LED devices (i.e. from near UV to blue LED).

For the different DNNDs, a charge transfer transition (HOMO $\rightarrow$ LUMO) is found for the lowest energy transition in agreement with their good light absorption properties. Indeed, for DNND1 to DNND4, the Highest Occupied Molecular Orbital (HOMO) and Lowest Unoccupied Molecular Orbital (LUMO) are clearly localized on the amino substituent and on the naphthalimide moiety, respectively (Fig. 2). For DNND5, such a charge transfer transition is also found but the HOMO and LUMO are more delocalized on the $\pi$ scaffold.

\section{Photoinitiating ability of the DNND based photoinitiating} systems

DNNDs for the cationic photopolymerization of epoxides. The DNNDs were combined with various additives (i.e. Iod and NVK) to initiate the ring-opening CP of EPOX under air using different irradiation devices (i.e. a halogen lamp or LEDs centered at $365 \mathrm{~nm}, 385 \mathrm{~nm}, 405 \mathrm{~nm}, 455 \mathrm{~nm}$ or $470 \mathrm{~nm})$. Fig. 3 displays some typical conversion-time profiles for the CP of EPOX and the final epoxy function conversions FC at $t=$ $800 \mathrm{~s}$ are summarized in Table 1. DNND2 exhibited light absorption only in the UV range; however, the DNND2 based systems (DNND2/Iod or DNND2/Iod/NVK) cannot initiate the polymerization of EPOX under the LED at $365 \mathrm{~nm}$ irradiation due to their poor light absorption properties and the low light intensity of this LED@365 nm $\left(\sim 18 \mathrm{~mW} \mathrm{~cm}^{-2}\right)$. With the DNND1 (or DNND4)/Iod combination, no polymerization was observed under the LED at $405 \mathrm{~nm}$ irradiation. The addition of NVK (as in previously reported photoinitiating systems ${ }^{45}$ ) significantly enhanced the FC (36\% and 63\% for DNND1 and DNND4 based systems, respectively). DNND4/Iod/NVK also worked well under the LED at $455 \mathrm{~nm}$ irradiation $(\mathrm{FC}=57 \%$, curve 6 in Fig. 3). Remarkably, the DNND3/Iod and DNND5/ Iod two-component systems already exhibited an excellent efficiency: FC attained 66\% (curve 1 and curve 4 in Fig. 3 ) and tack-free polyether coatings were obtained after $800 \mathrm{~s}$ of irradiation (LED at $405 \mathrm{~nm}$ ) due to the excellent overlapping between their absorption spectra and the emission spectrum of the LED. Moreover, these two efficient systems resulted in relatively high monomer conversions (42\% and 43\%) under halogen lamp irradiation, while the CQ based reference systems (CQ/Iod or CQ/Iod/NVK) yielded no polymerization. Interestingly, the DNND3/Iod led to EPOX conversions of $44 \%$, $66 \%$ and $68 \%$ under LEDs at $385 \mathrm{~nm}, 455 \mathrm{~nm}$ and $470 \mathrm{~nm}$, respectively. After one week of storage at room temperature, the photoinitiating ability of DNND3/Iod did not change (Fig. S7(a) in the ESI†), indicating good shelf life stability of the formulations. By analogy with the general behavior of other previously investigated photoinitiating systems, ${ }^{30,32,33}$ the generation of cations, radical cations and radicals upon

Table 1 Epoxy function conversions obtained under air upon exposure to different light sources for $800 \mathrm{~s}$ in the presence of DNNDs/lod $(0.5 \% / 2 \%, \mathrm{w} / \mathrm{w})$ or DNNDs/lod/NVK $(0.5 \% / 2 \% / 3 \%, \mathrm{w} / \mathrm{w} / \mathrm{w})$

\begin{tabular}{|c|c|c|c|c|c|c|}
\hline PIS & LED (365 nm) & LED (385 nm) & LED (405 nm) & LED (455 nm) & LED $(470 \mathrm{~nm})$ & Halogen lamp \\
\hline DNND2/Iod & $\mathrm{np}^{a}$ & & & & & \\
\hline DNND5/Iod & & & $66 \%$ & & & $43 \%$ \\
\hline DNND1/Iod/NVK & & $15 \%$ & $36 \%$ & & & \\
\hline DNND2/Iod/NVK & $\mathrm{np}^{a}$ & & & & & \\
\hline
\end{tabular}

${ }^{a}$ np: no photopolymerization. ${ }^{b}$ Measured after one week of storage at room temperature. 
light exposure of the DNND/Iod and DNND/Iod/NVK systems can be safely described by the following set of reactions (r1)-(r5).

$$
\begin{aligned}
& \mathrm{DNND} \rightarrow{ }^{1} \mathrm{DNND}(h \nu) \text { and }{ }^{1} \mathrm{DNND} \rightarrow{ }^{3} \mathrm{DNND} \\
& { }^{1,3} \mathrm{DNND}+\mathrm{Ph}_{2} \mathrm{I}^{+} \rightarrow \mathrm{DNND}^{\cdot+}+\mathrm{Ph}_{2} \mathrm{I}^{\cdot} \\
& \mathrm{Ph}_{2} \mathrm{I}^{\bullet} \rightarrow \mathrm{Ph}^{\bullet}+\mathrm{Ph}-\mathrm{I} \\
& \mathrm{Ph}^{\bullet}+\mathrm{NVK} \rightarrow \mathrm{Ph}^{-\mathrm{NVK}}{ }^{\circ}
\end{aligned}
$$

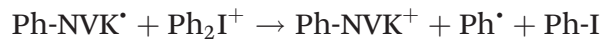

DNNDs in the free radical photopolymerization of an acrylate. The ability of the DNND based photoinitiating systems (consisting of one, two or three components) to initiate the FRP of TMPTA in laminate or under air was also investigated. Typical conversion-time profiles for the FRP of TMPTA in laminate upon exposure to different LEDs are shown in Fig. 4 and the final acrylate function conversions FC are listed in Table 2. As illustrated in Fig. 4(a), when using the LED at $405 \mathrm{~nm}$ : (i) DNND3 alone was capable of initiating the TMPTA polymerization but led to a low FC (25\%); (ii) the DNND1/R-Cl,
DNND2/Iod (even though it cannot work under LED@365 nm, it does under LED@405 nm due to the high light intensity of this LED) and DNND4/Iod two-component systems also led to relatively low polymerization rates and conversions $(\mathrm{FC}=$ 29-41\%, curves 1, 2 and 7); (iii) the DNND3/R-Cl and DNND3/ Iod were more efficient and yielded excellent final conversions (60\% and 57\%, respectively, curves 4 and 5 in Fig. 4(a)) slightly better than those reached with the popular commercial photoinitiator BAPO (56\%); (iv) interestingly, a noticeable bleaching in the presence of DNND4/Iod (Table S1 in the ESI $\dagger$ ) was observed after the photopolymerization, which endows the system with potential applications in the manufacture of colorless coatings; (v) the addition of NVK to the DNND3/Iod or DNND4/Iod system significantly increased the polymerization efficiency, leading to final conversions of $63 \%$ and $55 \%$, respectively (curve 5 vs. curve 6, curve $7 v s$. curve 8 in Fig. 4(a)); (vi) a high FC (61\%) was also found when using the DNND5/ MDEA/R-Cl combination.

TMPTA was also polymerized under LED@385 nm irradiation: DNND1/R-Cl presented a slightly better efficiency than under LED@405 nm, while the opposite was found with DNND3/Iod (Fig. 4(b) and S8, $\dagger$ curves 1 and 2). When the LED
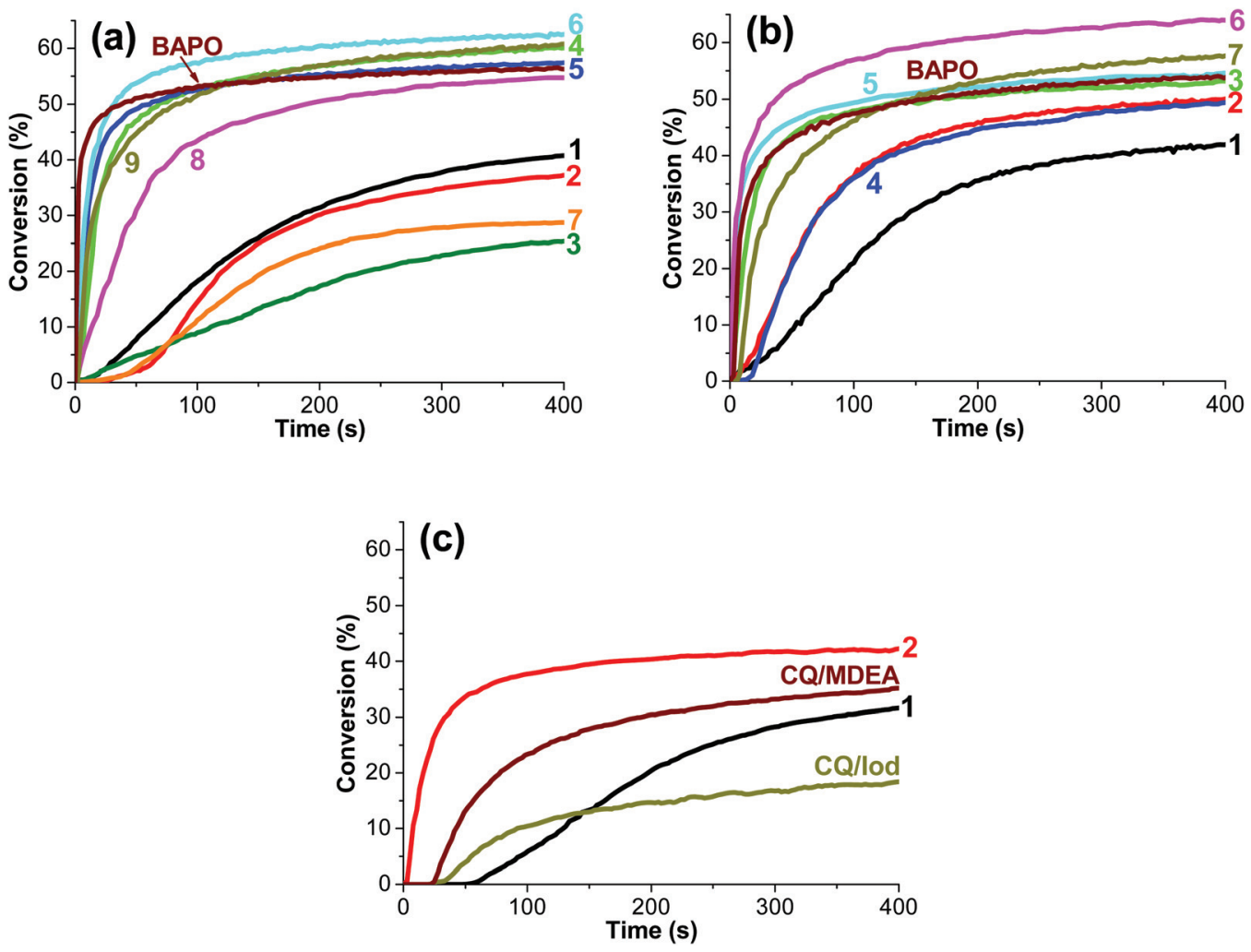

Fig. 4 Photopolymerization profiles of TMPTA (acrylate function conversion vs. time) in laminate in the presence of DNND based PISs: (a) DNND1/ R-Cl (curve 1), DNND2/lod (curve 2), DNND3 (curve 3), DNND3/R-Cl (curve 4), DNND3/lod (curve 5), DNND3/lod/NVK (curve 6), DNND4/lod (curve 7), DNND4/lod/NVK (curve 8), DNND5/MDEA/R-Cl (curve 9) upon exposure to a LED at $405 \mathrm{~nm}$; (b) DNND1/R-Cl (curve 1) or DNND3/lod (curve 2) upon exposure to a LED at $385 \mathrm{~nm}$; DNND3/lod (curve 3), DNND4/lod/NVK (curve 4), DNND5/R-Cl (curve 5) or DNND5/MDEA/R-Cl (curve 6) upon exposure to a LED at $455 \mathrm{~nm}$; DNND5/MDEA/R-Cl upon exposure to a LED at $470 \mathrm{~nm}$ (curve 7); (c) DNND3/R-Cl (curve 1) or DNND5/R-Cl (curve 2) upon exposure to a halogen lamp; $C Q / \operatorname{lod}(0.5 \% / 2 \%, w / w)$ or CQ/MDEA $(0.5 \% / 2 \%, w / w)$ upon halogen lamp exposure and BAPO $(0.5$ wt $\%)$ upon LEDs at $405 \mathrm{~nm}$ (a) or $455 \mathrm{~nm}$ (b) exposure as references; DNNDs: $0.5 \mathrm{wt} \%$; lod or MDEA: 2 wt\%; NVK or R-Cl: 3 wt\% in the formulations. 
Table 2 Acrylate function conversions obtained in laminate upon exposure to different light sources for $400 \mathrm{~s}$ in the presence of DNND based PISs (DNNDs: $0.5 \mathrm{wt} \%$; lod or MDEA 2 wt\%; NVK or R-Cl: 3 wt\% in the formulations); CQ/lod $(0.5 \% / 2 \%, w / w), C Q / M D E A(0.5 \% / 2 \%, w / w)$ and BAPO (0.5 wt\%) PISs as references

\begin{tabular}{|c|c|c|c|c|c|}
\hline PIS & LED (385 nm) & LED (405 nm) & LED $(455 \mathrm{~nm})$ & LED (470 nm) & Halogen lamp \\
\hline DNND1/R-Cl & $42 \%$ & $41 \%$ & & & \\
\hline DNND2/Iod & & $37 \%$ & & & \\
\hline DNND3/R-Cl & & $60 \%$ & & & $32 \%$ \\
\hline DNND3/Iod & $50 \%$ & $57 \%$ & $53 \%$ & & \\
\hline DNND3/Iod/NVK & & $63 \% / 63 \%{ }^{b}$ & & & \\
\hline DNND4/Iod & & $29 \%$ & & & \\
\hline DNND5/R-Cl & & & $54 \% / 54 \%{ }^{b}$ & & $42 \%$ \\
\hline DNND5/MDEA/R-Cl & & $61 \%$ & $64 \% / 61 \%^{b}$ & $58 \%$ & \\
\hline BAPO & & $56 \%$ & $54 \%$ & & \\
\hline CQ/Iod & & & & & $18 \%$ \\
\hline CQ/MDEA & & & & & $35 \%$ \\
\hline
\end{tabular}

at $455 \mathrm{~nm}$ was used, DNND3/Iod, DNND5/R-Cl and DNND5/ MDEA/R-Cl demonstrated a similar or better efficiency $(\mathrm{FC}=$ 53-64\%, Fig. 4(b) and S8, $\dagger$ curves 3, 5 and 6) than the BAPO reference photoinitiator $(\mathrm{FC}=54 \%)$. DNND5/MDEA/R-Cl also worked well upon exposure at $470 \mathrm{~nm}$ and produced $\mathrm{FC}=$ $58 \%$. Compared to the CQ/Iod reference system $(\mathrm{FC}=18 \%)$, DNND3/Iod and DNND5/R-Cl were more efficient, and led to higher FC $(\geq 32 \%$, Fig. 4(c)) under soft halogen lamp irradiation. DNND5/R-Cl also exhibited a better efficiency than another CQ based reference system (CQ/MDEA). A good storage stability was found (see Fig. S7 in the ESI $\dagger$ ) for the photocurable acrylate formulations containing various DNND based photoinitiating systems (i.e. DNND3/Iod/NVK, DNND5/ $\mathrm{R}-\mathrm{Cl}$ and DNND5/MDEA/R-Cl). The R-Cl and MDEA additives function on the basis of reactions (r6)-(r10) as already proposed in other systems. ${ }^{30,46}$

${ }^{1,3} \mathrm{DNND}_{\rightarrow} \mathrm{DNND}^{\bullet-}+\mathrm{DNND}^{\cdot+} \rightarrow \mathrm{DNND}^{-\mathrm{H}^{\bullet}+\mathrm{DNND}_{(-\mathrm{H})}} \cdot$

$$
\begin{aligned}
& { }^{1,3} \mathrm{DNND}^{+} \mathrm{MDEA} \rightarrow \mathrm{DNND}^{\cdot-}+\mathrm{MDEA}^{\cdot+} \\
& \rightarrow \mathrm{DNND}^{-\mathrm{H}^{\bullet}}+\operatorname{MDEA}_{(-\mathrm{H})}{ }^{\bullet} \\
& \mathrm{DNND}^{\bullet-}\left(\text { or DNND }-\mathrm{H}^{\bullet}\right)+\mathrm{R}-\mathrm{Cl} \\
& \rightarrow \text { DNND }\left(\text { or DNND }+\mathrm{H}^{+}\right)+(\mathrm{R}-\mathrm{Cl})^{\cdot-} \\
& { }^{1,3} \mathrm{DNND}+\mathrm{R}-\mathrm{Cl} \rightarrow \mathrm{DNND}^{\bullet+}+(\mathrm{R}-\mathrm{Cl})^{\bullet-} \\
& (\mathrm{R}-\mathrm{Cl})^{\cdot-} \rightarrow \mathrm{R}^{\cdot}+\mathrm{Cl}^{-}
\end{aligned}
$$

DNNDs for the IPN synthesis: photopolymerization of EPOX/TMPTA blends. The DNND4/Iod/NVK combination was able to initiate the concomitant cationic/radical polymerization of an EPOX/TMPTA blend (50\%/50\% w/w) upon exposure to a LED at $405 \mathrm{~nm}$ (Fig. 5), leading to the formation of an interpenetrating polymer network (IPN). A high efficiency was found within $800 \mathrm{~s}$ : $\mathrm{FC}=70 \%$ for epoxy functions and $\mathrm{FC}=$ $51 \%$ for acrylate functions under air; $\mathrm{FC}=40 \%$ for epoxy and FC $=75 \%$ for acrylate in laminate. Similar to the observed behavior with other photoinitiating systems, ${ }^{35,47}$ the final
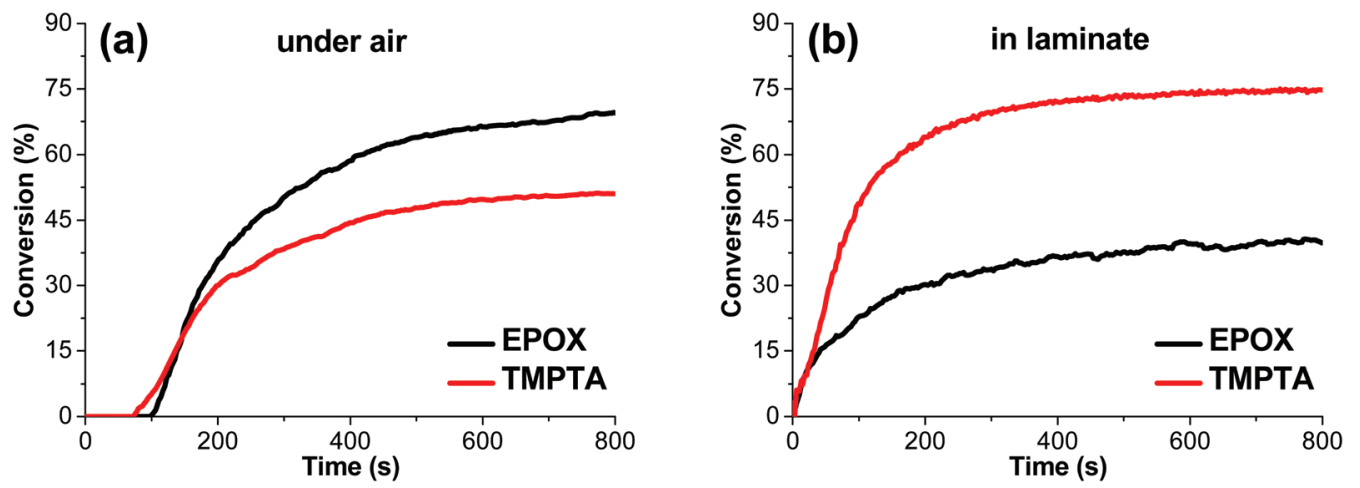

Fig. 5 Photopolymerization profile of an EPOX/TMPTA blend $(50 \% / 50 \%, w / w)$ in the presence of DNND4/lod/NVK $(0.5 \% / 2 \% / 3 \%$, w/w/w) under air (a) or in laminate (b) upon LED at $405 \mathrm{~nm}$ exposure (conversion of epoxy (or acrylate) function vs. time). 


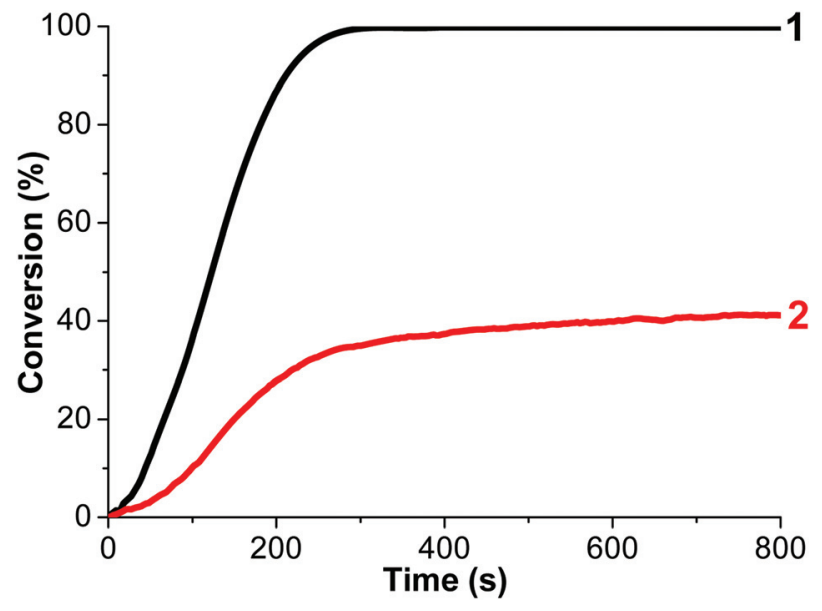

Fig. 6 Photopolymerization profile of a trithiol/DVE-3 blend $(40 \% / 60 \%$, $\mathrm{n} / \mathrm{n} ; 57 \% / 43 \%, \mathrm{w} / \mathrm{w})$ in laminate in the presence of DNND4/lod $(0.5 \% /$ $2 \%, \mathrm{w} / \mathrm{w}$ ) upon LED at $405 \mathrm{~nm}$ exposure; curve 1: DVE-3 (vinyl double bond) conversion; curve 2: trithiol (S-H) conversion.

conversions were higher in laminate for TMPTA and under air for EPOX. Tack free coatings were obtained after $8 \mathrm{~min}$ of LED irradiation either in laminate or under air and the color of the coating became lighter after the polymerization (Table S1 $\dagger$ ).

DNNDs for a thiol-ene photopolymerization. The thiol-ene (trithiol/DVE-3) polymerization was also carried out using the DNND4/Iod system upon exposure to a LED at $405 \mathrm{~nm}$ (Fig. 6). A plausible mechanism is summarized in reactions (r1)-(r3) followed by reactions (r11)-(r13).

$$
\begin{gathered}
\mathrm{Ph}^{\bullet}+\mathrm{RS}-\mathrm{H} \rightarrow \mathrm{Ph}-\mathrm{H}+\mathrm{RS}^{\bullet} \\
\mathrm{RS}^{\bullet}+\mathrm{R}^{\prime}-\mathrm{CH}=\mathrm{CH}_{2} \rightarrow \mathrm{R}^{\prime}-\mathrm{CH}^{\bullet}-\mathrm{CH}_{2} \mathrm{SR}
\end{gathered}
$$

$$
\mathrm{R}^{\prime}-\mathrm{CH}^{\bullet}-\mathrm{CH}_{2} \mathrm{SR}+\mathrm{RS}-\mathrm{H} \rightarrow \mathrm{R}^{\prime}-\mathrm{CH}_{2}-\mathrm{CH}_{2} \mathrm{SR}+\mathrm{RS}^{\bullet}
$$

The low S-H conversion $(\sim 41 \%$ vs. $\sim 100 \%$ for the vinyl double bond after $800 \mathrm{~s}$ of light exposure) indicates a significant contribution of the cationic polymerization of DVE-3.

\section{Photochemistry of the DNND based photoinitiating systems}

The DNND/Iod interaction was qualitatively investigated using steady state photolysis experiments in acetonitrile (Fig. 7 and S9†). During the irradiation at $405 \mathrm{~nm}$ under air, a very fast bleaching of both DNND3/Iod (or R-Cl) and DNND5/Iod (or R-Cl) was observed within $20 \mathrm{~s}$ [Fig. 7(c), (e) and S9(b-2), (d-2); $\dagger$ for DNND4/Iod, a notable bleaching occurred, but at a moderate pace], whereas a photochemical stability of DNND1/ Iod and DNND2/Iod was noted (Fig. 7(a) and (b)): this is in line with the trend observed for the corresponding polymerization efficiencies.

The behaviors of the DNNDs in multi-component systems were further investigated by ESR spin trapping experiments. Phenyl radicals were clearly observed e.g. after the electron transfer in the DNND3/Iod couple (PBN spin adduct in Fig. 8; hfc: $a_{\mathrm{N}}=14.2 \mathrm{G} ; a_{\mathrm{H}}=2.2 \mathrm{G}$; reference values in ref. 48,49 ), which is consistent with the mechanism described in the set of reactions ( $\mathrm{r} 1)-(\mathrm{r} 3)$.

The first excited singlet state of the DNNDs $\left({ }^{1}\right.$ DNND) was characterized by fluorescence experiments. Long fluorescence lifetimes $(\tau)$ are critical for efficient interactions between ${ }^{1}$ DNND and the additives. As illustrated in Table 3 , the fluorescence quantum yields ( $\Phi_{\text {fluo }}$ ) largely depend on the substituents on the DNND skeleton and follow the trend: DNND2 < DNND1 < DNND4 < DNND5 < DNND3. The nitro derivative (DNND1), compared to the corresponding amino one (DNND3), has much lower $\Phi_{\text {fluo }}$ and $\tau$ values: DNND1 (5.2 ns) $<$ DNND3 (15.2 ns). The DNND1/Iod (or R-Cl) and DNND3/Iod
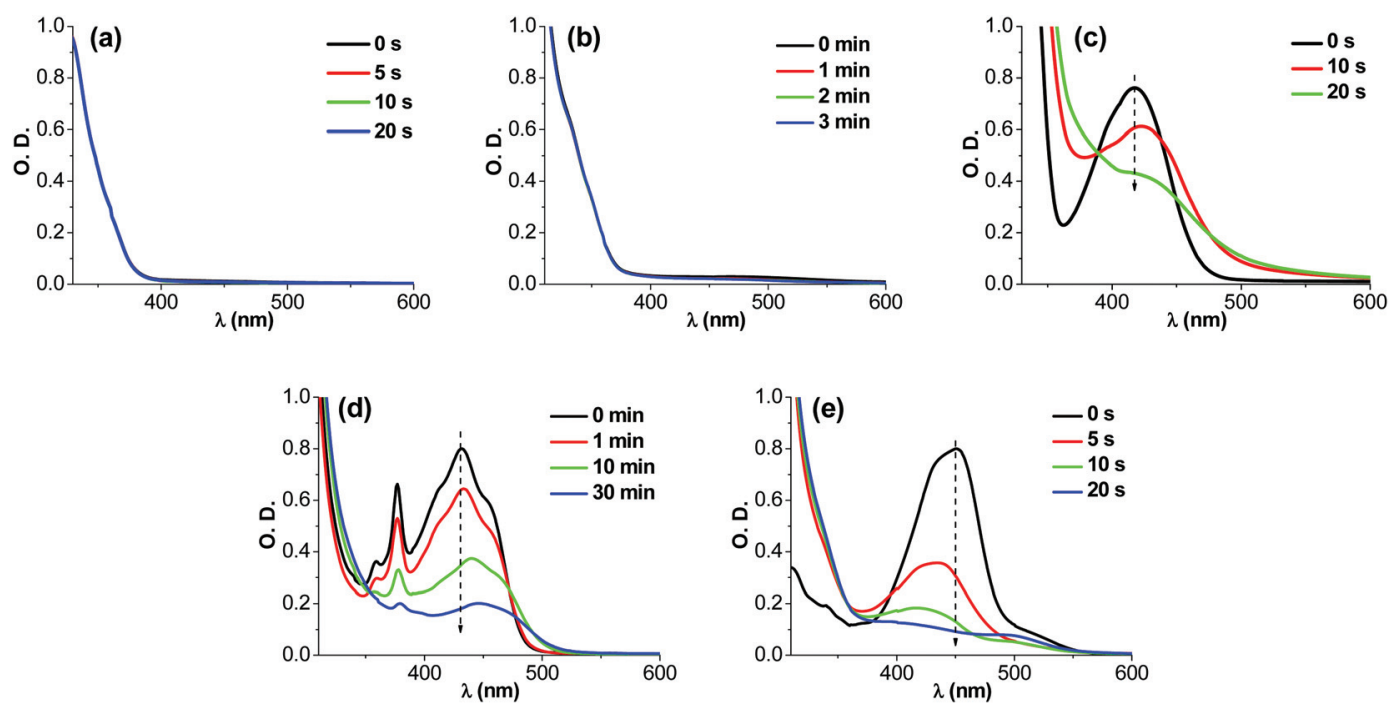

Fig. 7 Steady state photolysis of DNNDs/lod in acetonitrile: (a) DNND1/lod, (b) DNND2/lod, (c) DNND3/lod, (d) DNND4/lod and (e) DNND5/lod; UV-visible spectra recorded at different irradiation times. [lod] $=15 \mathrm{mM}$. Upon LED at $405 \mathrm{~nm}$ exposure. 


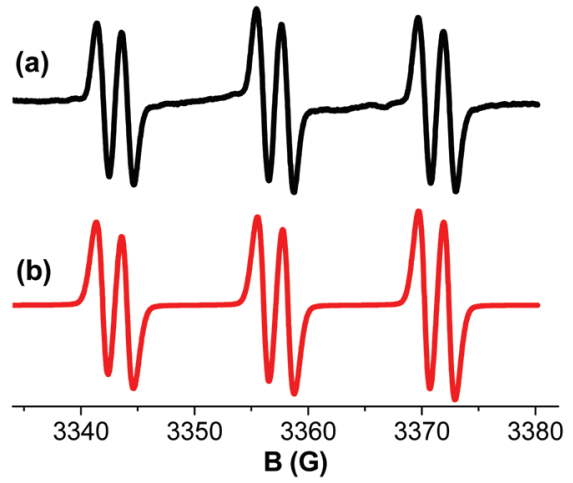

Fig. 8 ESR spectra of the radicals generated in DNND3/lod and trapped by PBN in tert-butylbenzene: (a) experimental and (b) simulated spectra.

(or $\mathrm{R}-\mathrm{Cl}$ ) interaction rate constants determined by fluorescence quenching experiments are almost diffusion-controlled: $k_{\mathrm{q}}=$ $11.3 \times 10^{9} \mathrm{M}^{-1} \mathrm{~s}^{-1}\left(16.4 \times 10^{9} \mathrm{M}^{-1} \mathrm{~s}^{-1}\right)$ and $3.2 \times 10^{9} \mathrm{M}^{-1} \mathrm{~s}^{-1}$ $\left(2 \times 10^{9} \mathrm{M}^{-1} \mathrm{~s}^{-1}\right)$, respectively. The free energy changes $\Delta G$ for the ${ }^{1}$ DNND1 ( ${ }^{1}$ DNND3, ${ }^{1}$ DNND4 or ${ }^{1}$ DNND5)/Iod (or R-Cl) electron transfer reactions (reactions (r2) and (r9)) are highly negative, which makes the processes favorable. This is also in full agreement with the high electron transfer quantum yields $\left(\Phi_{\mathrm{eT}}\right)$ found for reactions (r2) and (r9) (Table 3). Reactions (r2) and (r9) being favorable for all the DNNDs, their respective light absorption properties must be taken into account to explain the difference in their photoinitiating ability.

${ }^{1}$ DNND might undergo an intersystem crossing process to yield a triplet state $\left({ }^{3}\right.$ DNND). However, no DNND triplet state absorption was observed in the $400-700 \mathrm{~nm}$ range by laser flash photolysis experiments: this was probably due to a low intersystem crossing quantum yield. Therefore, the DNNDs likely react with the additives mainly in their singlet state (a triplet route remains, however, energetically favourable: see in Table $\left.3, \Delta G_{\mathrm{T}}<0\right)$.

\section{Polymerization in water for the synthesis of hydrogels}

Synthesis and characterization of the water soluble DNND/ SBE- $\beta$-CD complex. After having prepared the DNND derivatives and characterized their photoreactivity, we looked for an inclusion complexation strategy ${ }^{51-54}$ that would enable us to increase the water solubility of the PI enough to allow the photopolymerization reactions in water. After several unsuccessful trials, we managed to prepare an azonafide (DNND4) complex with sulfobutylether- $\beta$-cyclodextrin (SBE- $\beta$-CD, see ESI $\dagger) .{ }^{55}$ This modified $\beta$-cyclodextrin has several sulfobutylether moieties as a means to both enhance the solubility of the macrocyclic host and slightly extend the cavity size. This compound was found to greatly enhance the solubility of some drugs in pharmacological studies. ${ }^{1} \mathrm{H}$ NMR spectroscopy of DNND4 in water showed virtually no signals (Fig. 9).

However, the complex showed resonances in the aromatic region assigned to include DNND4 within the cavity of SBE$\beta$-CD. The ratio of integrals between guest aromatic protons and those of SBE- $\beta-C D$ is about $1 / 24$, reflecting a rather low but sufficient complexation capacity. The complexation can be seen visually since the brownish opaque suspension of DNND4 turned yellowish transparent after complexation (Fig. 10a, inset).

The fluorescence of DNND4 was found to be highly sensitive to the presence of SBE- $\beta$-CD in water and then fluorescence titrations were performed to estimate the binding constant (Fig. 10b). Considering that the observed fluorescence is a weighted contribution of that of free DNND4 and that of complexed DNND4 and using an adapted version for a $1: 1$ binding model (eqn (1)), ${ }^{56,57}$ the set of experimental points (intensity measured at $519 \mathrm{~nm}$ ) was fitted to this equation using a nonlinear curve fit and provided a binding

Table 3 Parameters characterizing the reactivity of the investigated DNNDs with various additives

\begin{tabular}{|c|c|c|c|c|c|c|c|c|c|}
\hline & $E_{\mathrm{S}}{ }^{a}(\mathrm{eV})$ & $E_{\mathrm{ox}}(\mathrm{V} v s . \mathrm{SCE})^{b}$ & $\Delta G_{\mathrm{s}}{ }^{c}(\mathrm{eV})$ & $E_{\mathrm{T}}^{d}(\mathrm{eV})$ & $\Delta G_{\mathrm{T}}^{c}(\mathrm{eV})$ & $k_{\mathrm{q}}{ }^{e}\left(\times 10^{9} \mathrm{M}^{-1} \mathrm{~s}^{-1}\right)$ & $\Phi_{\mathrm{eT}}^{f}$ & $\Phi_{\text {fluo }}^{g}$ & $\tau^{h}(\mathrm{~ns})$ \\
\hline DNND1/Iod & 2.96 & 0.83 & -1.93 & 2.26 & -1.23 & 11.3 & 0.73 & $5.6 \times 10^{-4}$ & 5.2 \\
\hline DNND1/R-Cl & 2.96 & 0.83 & -1.35 & 2.26 & -0.65 & 16.4 & 0.85 & $5.6 \times 10^{-4}$ & 5.2 \\
\hline DNND2 & & 0.72 & & 2.18 & & & & $9.8 \times 10^{-5}$ & \\
\hline DNND3/Iod & 2.68 & 0.62 & -1.86 & 2.03 & -1.21 & 3.2 & 0.69 & 0.16 & 15.2 \\
\hline DNND3/R-Cl & 2.68 & 0.62 & -1.28 & 2.03 & -0.63 & 2.0 & 0.68 & 0.16 & 15.2 \\
\hline DNND4/Iod & 2.66 & 0.59 & -1.87 & 1.59 & -0.8 & & & 0.012 & 15.0 \\
\hline DNND4/R-Cl & 2.66 & 0.59 & -1.29 & 1.59 & -0.22 & & & 0.012 & 15.0 \\
\hline DNND5/Iod & 2.59 & 0.52 & -1.87 & 1.76 & -1.04 & & & 0.017 & \\
\hline DNND5/R-Cl & 2.59 & 0.52 & -1.29 & 1.76 & -0.46 & & & 0.017 & \\
\hline
\end{tabular}

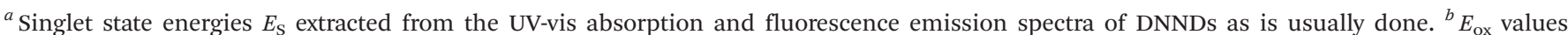

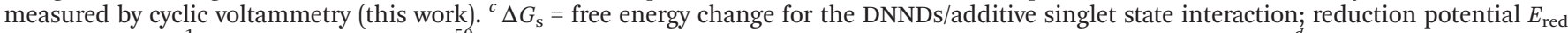

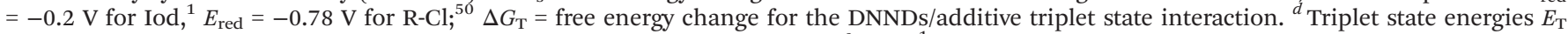

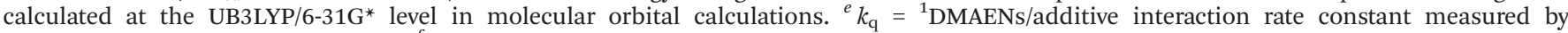

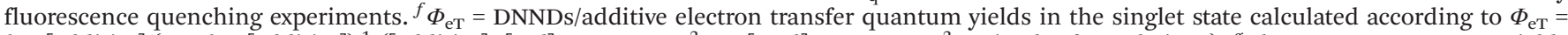

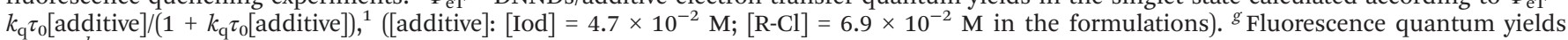
$\left(\Phi_{\text {fluo }}\right) .{ }^{h}$ Fluorescence lifetimes $(\tau)$. 
a)

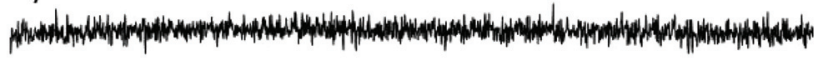

b)

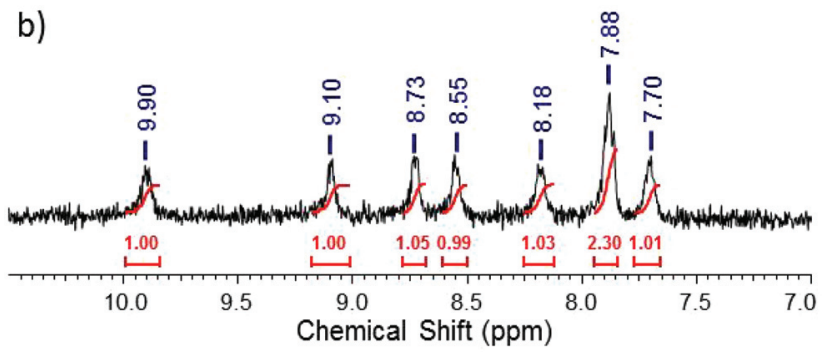

Fig. 9 (a) $400 \mathrm{MHZ}{ }^{1} \mathrm{H}$ NMR spectra of DNND4 alone (1 mM) and (b) that of the complex $(\sim 20 \mathrm{mM})$ in $\mathrm{D}_{2} \mathrm{O}$.
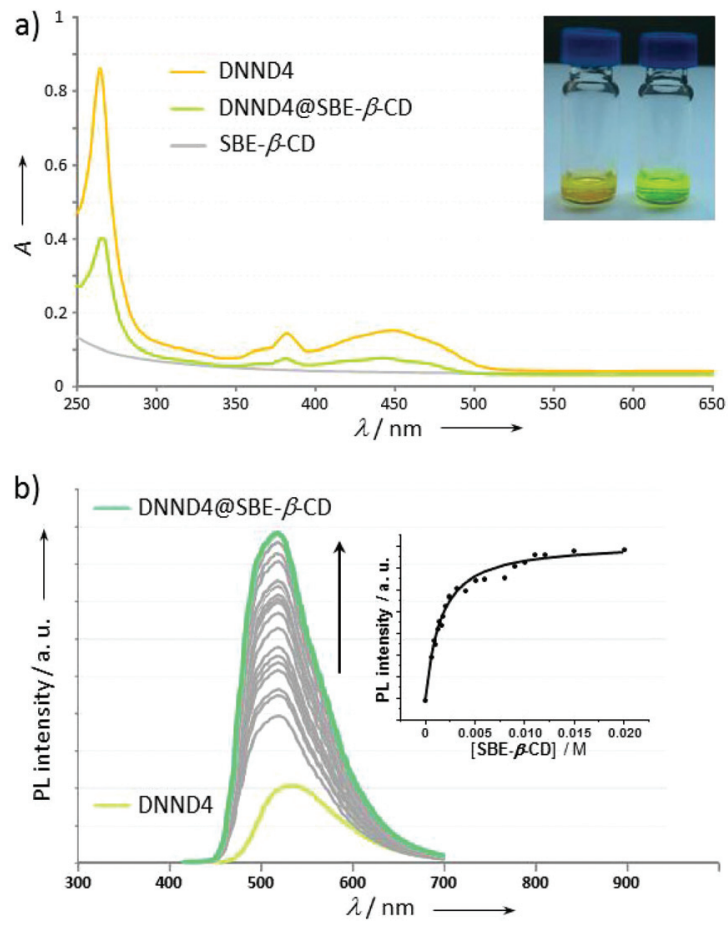

Fig. 10 (a) UV-vis spectra of DNND4 (0.1 mM), SBE- $\beta-C D(0.1 \mathrm{mM})$ and the complex $(0.1 \mathrm{mM}$ based on the molecular weight of SBE- $\beta-C D$ since the guest is highly diluted). (b) Fluorescence titration of DNND4 $(5 \times$ $10^{-4} \mathrm{M}$ ) with increasing concentration of SBE- $\beta$-CD (from $6 \times 10^{-4} \mathrm{M}$ to $20 \mathrm{mM} ; \lambda_{\text {exc }}=382 \mathrm{~nm}$ ).

constant $K_{\mathrm{a}}=796 \pm 60 \mathrm{M}^{-1}$ (Fig. 10b, inset) which is consistent with expected values: ${ }^{58,59}$

$$
\begin{aligned}
F_{x}= & F_{0}-\left(\frac{\Delta F}{2}\right) \\
& \times\left[\left(1+\frac{[\mathrm{H}]_{0}}{[\mathrm{G}]_{0}}+\frac{1}{K[\mathrm{G}]_{0}}\right)-\sqrt{\left(1+\frac{[\mathrm{H}]_{0}}{[\mathrm{G}]_{0}}+\frac{1}{K[\mathrm{G}]_{0}}\right)^{2}-4 \frac{[\mathrm{H}]_{0}}{[\mathrm{G}]_{0}}}\right.
\end{aligned}
$$

A

a) Before LED irradiation

b) After LED irradiation
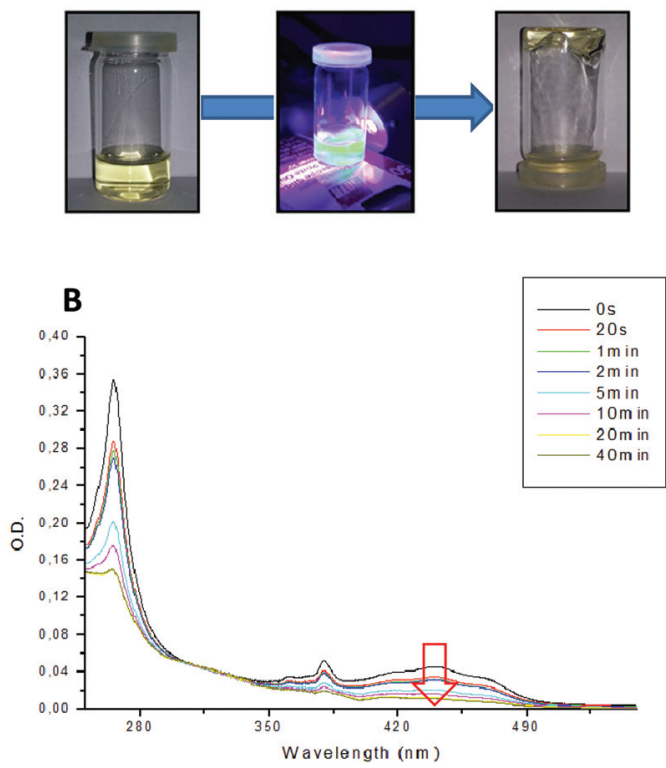

Fig. 11 (A) Description of the polymerization in water upon LED ( $405 \mathrm{~nm}$ irradiation; (B) photolysis of a DNND4/SBE- $\beta-C D / M D E A$ solution in water upon LED@405 $\mathrm{nm}$ irradiation.

The present results indicate that the hydrophobic DNND4 is included in the cavity of SBE- $\beta$-CD, which is reflected by the observable ${ }^{1} \mathrm{H}$ NMR resonances of the guest in the complex in water and the changes in UV and fluorescence spectra.

DNND4/SBE- $\beta$-CD/MDEA as a water soluble photoinitiating system. A Type II photoinitiating system [DNND4/SBE- $\beta$-CD $(0.3 \%) /$ MDEA $(4 \%)]$ was used for the photopolymerization of HEMA in water $([$ HEMA $]=1.5 \mathrm{M}$ in water). After $1 \mathrm{~h}$ of

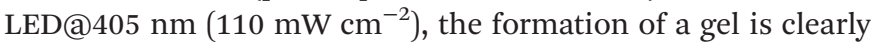
observed (Fig. 11A). Remarkably, it was not necessary to use an inert atmosphere, showing the high reactivity of the photoinitiating system to overcome the oxygen inhibition. The monomer conversion was determined gravimetrically $(\sim 68 \%)$ and the water content $(\sim 70 \%)$ for the synthesized hydrogels was determined by thermogravimetric measurements. Without MDEA or DNND4/SBE- $\beta$-CD, no polymerization occurs, showing that both components are crucial for an efficient photoinitiating system in agreement with reaction ( $r 7)$. In full agreement with (r7), a clear bleaching is observed for the photolysis of a DNND4/SBE- $\beta$-CD/MDEA solution in water (Fig. 11B). The photopolymerization of hydroxyethylacrylate (HEA) was also easily accessible under the same conditions as HEMA.

\section{Conclusion}

By changing the substituents on the $N$-[2-(dimethylamino)ethyl]-1,8-naphthalimide skeleton, the light absorption 
maxima were successfully shifted to the visible range. Upon exposure of the DNNDs in the presence of an iodonium salt (Iod), $N$-vinylcarbazole (NVK), an amine (MDEA or EDB) or 2,4,6-tris(trichloromethyl)-1,3,5-triazine (R-Cl) to various visible LED lights (centered at $405 \mathrm{~nm}, 455 \mathrm{~nm}$ and $470 \mathrm{~nm}$ ), radicals, cation radicals and cations were photochemically generated. The cationic polymerization of EPOX, the free radical polymerization of TMPTA, the EPOX/TMPTA blend IPN polymerization, and the trithiol/DVE-3 thiol-ene polymerization were achieved. Some of these DNND based photoinitiating systems (e.g. DNND3/Iod, DNND3/R-Cl) are more efficient than the well-known CQ based reference systems or BAPO. The synthesis of hydrogels was also feasible using a DNND derivative encapsulated in a cyclodextrin. This research extends the range of high-performance photoinitiating systems operating under violet to blue light. Other studies are in progress.

\section{Competing interest}

The authors declare no competing financial interest.

\section{Acknowledgements}

JL thanks the Institut Universitaire de France for the financial support.

\section{References}

1 J. P. Fouassier and J. Lalevée, Photoinitiators for Polymer Synthesis-Scope, Reactivity, and Efficiency, Wiley-VCH Verlag GmbH \& Co KGaA, Weinheim, 2012.

2 N. S. Allen, Photochemistry and photophysics of polymer materials, Wiley, USA, 2010.

3 J. V. Crivello and K. Dietliker, Photoinitiators for Free Radical, Cationic and Anionic Photopolymerization, John Wiley \& Sons, Chichester, 2nd edn, 1998.

4 J. P. Fouassier, Photoinitiator, Photopolymerization and Photocuring: Fundamentals and Applications, Hanser Publishers, New York/Munich/Vienna, 1995.

5 D. C. Neckers and W. Jager, Photoinitiation for Polymerization: $U V$ and EB at the Millenium, John Wiley \& Sons, Chichester, 1999, 410pp.

6 D. Neshchadin, A. Rosspeintner, M. Griesser, B. Lang, S. Mosquera-Vazquez, E. Vauthey, V. Gorelik, R. Liska, C. Hametner, B. Ganster, R. Saf, N. Moszner and G. Gescheidt, J. Am. Chem. Soc., 2013, 135, 17314-17321.

7 F. Sun, Y. Li, N. Zhang and J. Nie, Polymer, 2014, 55, 36563665 .

8 K. Kawamura, C. Ley, J. Schmitt, M. Barnet and X. Allonas, J. Polym. Sci., Part A: Polym. Chem., 2013, 51, 4325-4330.

9 H. Kitano, K. Ramachandran, N. B. Bowden and A. B. Scranton, J. Appl. Polym. Sci., 2013, 128, 611-618.

10 W. D. Cook and F. Chen, Polym. Chem., 2015, 6, 1325-1338.
11 J. Kabatc, K. Jurek, Z. Czech and A. Kowalczyk, Dyes Pigm., 2015, 114, 144-145.

12 D. Karaca Balta, Ö. Karahan, D. Avci and N. Arsu, Prog. Org. Coat., 2015, 78, 200-207.

13 G. Müller, M. Zalibera, G. Gescheidt, A. Rosenthal, G. Santiso-Quinones, K. Dietliker and H. Grützmacher, Macromol. Rapid Commun., 2015, 36, 553-557.

14 A. Aguirre-Soto, C.-H. Lim, A. T. Hwang, C. B. Musgrave and J. W. Stansbury, J. Am. Chem. Soc., 2014, 136, 74187427.

15 J. E. Klee, M. Maier and C. P. Fik, in Dyes and Chromophores in Polymer Science, ed. J. Lalevée and J.-P. Fouassier, John Wiley \& Sons, Inc., 2015, pp. 123-138.

16 R. Bongiovanni and M. Sangermano, in Encyclopedia of Polymer Science and Technology, John Wiley \& Sons, Inc., 2002.

17 B. Strehmel, T. Brömme, C. Schmitz, K. Reiner, S. Ernst and D. Keil, in Dyes and Chromophores in Polymer Science, ed. J. Lalevée and J.-P. Fouassier, John Wiley \& Sons, Inc., 2015, pp. 213-249.

18 C. I. Vallo and S. V. Asmussen, in Photocured Materials, ed. A. Tiwari and A. Polykarpov, The Royal Society of Chemistry, 2015, pp. 321-346.

19 J. Crivello, in Dyes and Chromophores in Polymer Science, ed. J. Lalevée and J.-P. Fouassier, John Wiley \& Sons, Inc., 2015, pp. 45-79.

20 S. Doran, O. S. Taskin, M. A. Tasdelen and Y. Yağci, in Dyes and Chromophores in Polymer Science, ed. J. Lalevée and J.-P. Fouassier, John Wiley \& Sons, Inc., 2015, pp. 81-121.

21 J. Torgersen, X.-H. Qin, Z. Li, A. Ovsianikov, R. Liska and J. Stampfl, Adv. Funct. Mater., 2013, 23, 4542-4554.

22 T. Gong, B. J. Adzima, N. H. Baker and C. N. Bowman, Adv. Mater., 2013, 25, 2024-2028.

23 B. P. Fors and C. J. Hawker, Angew. Chem., Int. Ed., 2012, 51, 8850-8853.

24 N. J. Treat, B. P. Fors, J. W. Kramer, M. Christianson, C.-Y. Chiu, J. R. d. Alaniz and C. J. Hawker, ACS Macro Lett., 2014, 3, 580-584.

25 T. G. Ribelli, D. Konkolewicz, S. Bernhard and K. Matyjaszewski, J. Am. Chem. Soc., 2014, 136, 1330313312.

26 N. Karaca, G. Temel, D. Karaca Balta, M. Aydin and N. Arsu, J. Photochem. Photobiol., A, 2010, 209, 1-6.

27 C. R. Rivarola, M. A. Biasutti and C. A. Barbero, Polymer, 2009, 50, 3145-3152.

28 J. Lalevee and J. P. Fouassier, Dyes and Chomophores in Polymer Science, ISTE Wiley, London, 2015.

29 J. Zhang, N. Zivic, F. Dumur, P. Xiao, B. Graff, J. P. Fouassier, D. Gigmes and J. Lalevée, Polymer, 2014, 55, 6641-6648.

30 J. Zhang, N. Zivic, F. Dumur, P. Xiao, B. Graff, D. Gigmes, J. P. Fouassier and J. Lalevée, J. Polym. Sci., Part A: Polym. Chem., 2015, 53, 445-451.

31 P. Xiao, F. Dumur, J. Zhang, B. Graff, D. Gigmes, J. P. Fouassier and J. Lalevée, Macromol. Chem. Phys., 2015, 216, 1782-1790. 
32 P. Xiao, F. Dumur, J. Zhang, B. Graff, D. Gigmes, J. P. Fouassier and J. Lalevée, J. Polym. Sci., Part A: Polym. Chem., 2015, 53, 665-674.

33 P. Xiao, F. Dumur, J. Zhang, B. Graff, D. Gigmes, J. P. Fouassier and J. Lalevee, Polym. Chem., 2015, 6, 11711179.

34 P. Xiao, F. Dumur, B. Graff, J. Zhang, F. Morlet-Savary, D. Gigmes, J. P. Fouassier and J. Lalevée, J. Polym. Sci., Part A: Polym. Chem., 2014, 53, 567-575.

35 P. Xiao, F. Dumur, B. Graff, D. Gigmes, J. P. Fouassier and J. Lalevée, Macromolecules, 2014, 47, 601-608.

36 S. M. Sami, R. T. Dorr, D. S. Alberts, A. M. Sólyom and W. A. Remers, J. Med. Chem., 2000, 43, 3067-3073.

37 J. B. Foresman and A. Frisch, Exploring Chemistry with Electronic Structure Methods, Gaussian, Inc., 1996.

38 M. J. Frisch, G. W. Trucks, H. B. Schlegel, G. E. Scuseria, M. A. Robb, J. R. Cheeseman, V. G. Zakrzewski, J. A. Montgomery, J. R. E. Stratmann, J. C. Burant, S. Dapprich, J. M. Millam, A. D. Daniels, K. N. Kudin, M. C. Strain, O. Farkas, J. Tomasi, V. Barone, M. Cossi, R. Cammi, B. Mennucci, C. Pomelli, C. Adamo, S. Clifford, J. Ochterski, G. A. Petersson, P. Y. Ayala, Q. Cui, K. Morokuma, P. Salvador, J. J. Dannenberg, D. K. Malick, A. D. Rabuck, K. Raghavachari, J. B. Foresman, J. Cioslowski, J. V. Ortiz, A. G. Baboul, B. B. Stefanov, G. Liu, A. Liashenko, P. Piskorz, I. Komaromi, R. Gomperts, R. L. Martin, D. J. Fox, T. Keith, M. A. Al-Laham, C. Y. Peng, A. Nanayakkara, M. Challacombe, P. M. W. Gill, B. Johnson, W. Chen, M. W. Wong, J. L. Andres, C. Gonzalez, M. Head-Gordon, E. S. Replogle and J. A. Pople, Gaussian 03, Revision B-2, Gaussian, Inc., Pittsburgh, PA, 2003.

39 M.-A. Tehfe, J. Lalevée, S. Telitel, J. Sun, J. Zhao, B. Graff, F. Morlet-Savary and J.-P. Fouassier, Polymer, 2012, 53, 2803-2808.

40 M. A. Tehfe, J. Lalevée, F. Morlet-Savary, B. Graff, N. Blanchard and J. P. Fouassier, Macromolecules, 2012, 45, 1746-1752.

41 S. Erdur, G. Yilmaz, D. Goen Colak, I. Cianga and Y. Yagci, Macromolecules, 2014, 47, 7296-7302.

42 D. Rehm and A. Weller, Isr. J. Chem., 1970, 8, 259-271.
43 P. Xiao, J. Lalevée, X. Allonas, J. P. Fouassier, C. Ley, M. El Roz, S. Q. Shi and J. Nie, J. Polym. Sci., Part A: Polym. Chem., 2010, 48, 5758-5766.

44 J. Lalevée, N. Blanchard, M. A. Tehfe, M. Peter, F. MorletSavary, D. Gigmes and J. P. Fouassier, Polym. Chem., 2011, 2, 1986-1991.

45 J. Lalevée, M.-A. Tehfe, A. Zein-Fakih, B. Ball, S. Telitel, F. Morlet-Savary, B. Graff and J. P. Fouassier, ACS Macro Lett., 2012, 1, 802-806.

46 P. Xiao, J. Zhang, F. Dumur, M. A. Tehfe, F. Morlet-Savary, B. Graff, D. Gigmes, J. P. Fouassier and J. Lalevée, Prog. Polym. Sci., 2015, 41, 32-66.

47 P. Xiao, F. Dumur, B. Graff, F. Morlet-Savary, D. Gigmes, J. P. Fouassier and J. Lalevée, Macromolecules, 2014, 47, 973-978.

48 M. A. Tehfe, J. Lalevée, S. Telitel, E. Contal, F. Dumur, D. Gigmes, D. Bertin, M. Nechab, B. Graff, F. Morlet-Savary and J. P. Fouassier, Macromolecules, 2012, 45, 4454-4460.

49 J. Lalevée, N. Blanchard, M. A. Tehfe, F. Morlet-Savary and J. P. Fouassier, Macromolecules, 2010, 43, 10191-10195.

50 G. Wallraff, M. Baier, A. Diaz and R. Miller, J. Inorg. Organomet. Polym., 1992, 2, 87-102.

51 J. Szejtli, Chem. Rev., 1998, 98, 1743-1754.

52 J. Lagona, P. Mukhopadhyay, S. Chakrabarti and L. Isaacs, Angew. Chem., Int. Ed., 2005, 44, 4844-4870.

53 D. Bardelang, G. Casano, F. Poulhès, H. Karoui, J. Filippini, A. Rockenbauer, R. Rosas, V. Monnier, D. Siri, A. GaudelSiri, O. Ouari and P. Tordo, J. Am. Chem. Soc., 2014, 136, 17570-17577.

54 D. Bardelang, A. Rockenbauer, H. Karoui, J.-P. Finet, I. Biskupska, K. Banaszak and P. Tordo, Org. Biomol. Chem., 2006, 4, 2874-2882.

55 V. J. Stella and Q. He, Toxicol. Pathol., 2008, 36, 30-42.

56 D. Bardelang, J.-L. Clément, J.-P. Finet, H. Karoui and P. Tordo, J. Phys. Chem. B, 2004, 108, 8054-8061.

57 R. S. Macomber, J. Chem. Educ., 1992, 69, 375.

58 G. Zhang, S. Shuang, Z. Dong, C. Dong and J. Pan, Anal. Chim. Acta, 2002, 474, 189-195.

59 S. Shityakov, I. Puskás, K. Pápai, E. Salvador, N. Roewer, C. Förster and J.-A. Broscheit, Molecules, 2015, 20, 1026410269. 